\title{
UK Renal Registry 20th Annual Report: Appendix A The UK Renal Registry Statement of Purpose
}

1. Executive summary

2. Introduction

3. Statement of intent

4. Relationships of the UK Renal Registry

5. The role of the UK Renal Registry for patients

6. The role of the UK Renal Registry for nephrologists

7. The role of the UK Renal Registry for trust managers

8. The role of the UK Renal Registry for commissioning agencies

9. The role of the UK Renal Registry in national quality assurance schemes

10. References

\section{A:1 Executive summary}

1.1 The UK Renal Registry (UKRR) was established by the Renal Association to act as a resource in the development of patient care in renal disease.

1.2 The UKRR acts as a source of comparative data for audit, benchmarking, planning, quality improvement, policy and research. The collection and analysis of sequential biochemical and haematological data is a unique feature of the UKRR.

1.3 The UK Renal Registry Database System Specification (UKRR DSS) defines the data items that are required to be sent from participating renal centres for analysis by the UKRR.

1.4 Data is collected quarterly to maintain centre-level quality assurance, with the results being published in an annual report.

1.5 Core activity is funded from commissioning agencies by a capitation fee per renal patient.

\begin{tabular}{ll}
\hline KARGER & $\begin{array}{l}\text { C } 2018 \text { The UK Renal Registry } \\
\text { Published by S. Karger AG, Basel }\end{array}$ \\
$\begin{array}{l}\text { Fax +41 } 613061234 \\
\text { E-Mail karger@karger.com } \\
\text { www.karger.com/nef }\end{array}$ & $\begin{array}{l}\text { This article is licensed under the Creative Commons Attribution- } \\
\text { NonCommercial-NoDerivatives } 4.0 \text { International License (CC BY- } \\
\text { NC-ND) (http://www.karger.com/Services/OpenAccessLicense). } \\
\text { Usage and distribution for commercial purposes as well as any } \\
\text { distribution of modified material requires written permission. }\end{array}$
\end{tabular}

1.6 As part of its core activities, the UKRR provides data to hospital trusts, commissioning authorities and the European Renal Association - European Dialysis and Transplant Association (ERAEDTA) Registry.

1.7 The development of the UKRR is open to influence from all interested parties, including clinicians, hospital trusts, commissioning authorities, patient groups, researchers and academics.

1.8 The UKRR is non-profit making and has a registered charitable status through the Renal Association.

\section{A:2 Introduction}

2.1 Registry-based national specialty comparative audit is one of the cornerstones of NHS development. The Renal National Service Framework (NSF), published in two sections in 2004 and 2005, recommended the participation of all renal centres in comparative audit through the UKRR.

2.2 The chief executives of hospital trusts are responsible for clinical governance and audit is an essential part of that agenda [1].

2.3 Demographic information on patients receiving renal replacement therapy (RRT) throughout Europe was collected from 1965 in the registry of the ERA-EDTA. This voluntary exercise was conducted on paper and by post, demanded considerable effort and time from participating centres and eventually proved impossible to sustain. Latterly, the incompleteness of UK data returns to

UK Renal Registry, Southmead Hospital, Southmead Road, Bristol, BS10 5NB, UK

Email: renalregistry@renalregistry.nhs.uk 
the ERA-EDTA made it impossible to build a picture of the activity of RRT in the UK for planning and policy purposes. Subsequently, national data collections from England and Wales were solicited from renal centres in 1992, 1996, 1999, 2002 and 2004 to fill this gap. The UKRR published its first report in 1998 and through its quarterly returns has established a system to place routine data collection and analysis on a permanent basis. The next stage is in progress incorporating data from the earlier stages of chronic kidney disease and acute kidney injury.

2.4 Together with the need to know demographic and structural elements, the NHS has developed a need to underpin clinical activity more rigorously through the scientific evidence base (for example, the Cochrane Initiative) and by quality assurance activity through audit. These initiatives require comprehensive information about the structures, processes and outcomes of RRT, which go well beyond the detail previously compiled by the ERA-EDTA.

2.5 The UKRR is recognised as one of the very few high quality clinical databases available for general use [2]. The collection of data by download of electronic records from routine clinical databases has been highly successful and is being imitated worldwide.

2.6 The Renal Association publishes guidelines in renal Clinical Standards documents. It was apparent during the development of the standards that many of the desirable criteria of clinical performance were uncertain or unknown and that only the accumulated data of practicing renal centres could provide the evidence for advice on best practice and what might be achievable. A common data registration provides the simplest device for such an exercise. The data currently gathered audits a proportion of the Renal Association standards, partly due to some data items required not being available in the dataset and partly due to data not being either completed in or extracted from renal systems. The dataset is subject to regular review and a drive is required for more complete data returns by renal centres.

2.7 It can be seen that the need for a RRT registry developed for a variety of reasons: international comparisons, national planning, local trust and health authority management, standard setting, audit and research. The opportunity for data gath- ering arises partly from improvements in information technology. Although it was possible to see the need for a national renal database over 25 years ago, the circumstances have become ideal for the maintenance of a data repository, supported by the clinical users and resourced for national benchmarking as a routine part of RRT management.

2.8 The provisional expectations of the earlier UKRR Annual Reports can now be replaced by confident assertions, built on the experience of nineteen years of publication, about the role and potential of the UKRR. The integration of the various elements of Renal Association strategy is being pursued through the Clinical Affairs Board (CAB) and Academic Affairs Board (AAB).

\section{A:3 Statement of intent}

The UKRR provides a focus for the collection and analysis of standardised data relating to the incidence, clinical management and outcome of renal disease. Data will be accepted quarterly by automatic downloading from renal centre databases. There will be a core dataset, with optional elements of special interest that may be entered by agreement for defined periods. A report will be published annually to allow a comparative audit of facilities, patient demographics, quality of care and outcome measures. Participation is mandated in England through the recommendation in the Renal National Service Framework and the NHS Commissioning document A06 Renal Dialysis. During the earlier years of the UKRR there was a focus on RRT, including transplantation, this now extends to other areas of nephrology. The UKRR provides an independent source of data and analysis on national activity in renal disease.

\section{A:4 Relationships of the UK Renal Registry}

4.1 The UKRR is a registered charity through the Renal Association (No. 2229663). It was established by a committee of the Renal Association, with additional representation from the British Transplantation Society, the British Association for Paediatric Nephrology, the Scottish Renal Registry, Wales and Northern Ireland. The UKRR maintains links 
with the Department of Health, the National Kidney Federation (NKF), Kidney Care UK (formerly the British Kidney Patient Association (BKPA)), the Royal Colleges, the Association for Clinical Biochemistry and Health and Social Care Commissioners.

4.2 A number of sub-committees were instituted as the database and renal centre participation developed, in particular for data analysis and interpretation for inclusion in the annual reports. Further specialised panels may be developed for publications and the dissemination of UKRR analyses.

4.3 The Scottish Renal Registry sends data to the UKRR for joint reporting and comparison.

4.4 The return of English, Welsh and Northern Irish data to the ERA-EDTA Registry will be through the UKRR. The Scottish Renal Registry already sends data directly to the ERA-EDTA Registry.

4.5 A paediatric database has been developed in collaboration with the UKRR. The two databases are in the process of being integrated, which will allow long-term studies of renal cohorts over a wide age range.

4.6 Close collaboration with NHS Blood and Transplant gives joint benefits. Data aggregation and integration has led to joint presentations and publications. The description of the entire patient pathway in RRT by this means is a source of continuing insight and usefulness.

4.7 The retention of patient identifiable information, necessary in particular for the adequate tracing of patients, has been approved by the Health Research Authority's Confidentiality Advisory Group (CAG). This is renewed on an annual basis along with audit of the information governance arrangements within the UKRR through completion of NHS Digital's Information Governance Toolkit.

\section{A:5 The role of the UK Renal Registry for patients}

5.1 The goal of the UKRR is to improve care for patients with renal disease. The appropriate use of UKRR information should improve equity of access to care, adequacy of facilities, availability of important but high cost therapies and the efficient use of resources. The continuing comparative audit of the quality of care should facilitate the improvement of care and treatment outcomes.
5.2 A patient leaflet and poster produced in collaboration with the NKF and Kidney Care UK are available on the UKRR website (www.renalreg.org), explaining how patients may opt-out of the collection of identifiable data by the UKRR if they wish. This was renewed in 2016 as part of the UKRR's CAG submission. Patient opt-out remains low.

5.3 Information from the UKRR complements the records available on 'PatientView' www.patientview.org.

5.4 A patient council has been convened. The role of the Patient Council is to:

- Act as representatives for kidney patients and their carers.

- Guide and influence methods of delivery of care.

- Advise on opportunities for new work ideas and initiatives for the UKRR.

- Contribute to the development of new audit, research and survey proposals.

- Provide an arena that will encourage discussions between patients and clinical teams to promote patient involvement at renal centre, regional and national levels.

- Monitor and review patient facing initiatives recommended by the Department of Health.

- Review applications and contribute towards the production of patient leaflets, posters, reports and other patient information products developed by the Renal Association.

- Support the UKRR in issues relating to information governance and patient consent.

- Use personal networks to spread awareness of the UKRR and its work with the council.

- Represent the Patient Council and the UKRR at other external meetings.

\section{A:6 The role of the UK Renal Registry for nephrologists}

6.1 The clinical community have become increasingly aware of the need to define and understand their activities, particularly in relation to national standards and in comparison with other renal centres.

6.2 In 2013, the UKRR Committee was disbanded and the UKRR is now governed by the Renal Information Governance Board of the Renal Association.

6.3 The Renal Standards documents are designed to give a basis for centre structure and performance, as well as patient-based elements such as case mix 
and outcomes. It is anticipated that Standards will become increasingly based on research evidence.

6.4 The UKRR data are available to allow the comparative review of many elements of renal centre practice. Centre data are presented to allow a contrast of individual centre activity and results against national aggregated data. Sophisticated analyses of patient survival for example, are a unique resource to exclude any anomalies of performance and standardise for centre caseload.

6.5 Reports of demographic and treatment variables are available to the participating centres for distribution to hospital trusts, strategic health authorities and commissioners, as well as renal networks, as required and agreed with the centre. Reports should facilitate discussion between clinicians, Trust officers and commissioners.

6.6 The UKRR welcomes suggestions for topics of national audit or research that colleagues feel are of sufficiently widespread interest for the UKRR to undertake.

6.7 The database has been designed to provide research facilities and for future participation in national and international trials. Members of the Renal Association and other interested parties are welcome to apply to the UKRR to conduct local or national audit and research using the database, further information is available at www.renalreg.org/about-us/ working-with-us/. All such projects will need the agreement of the UKRR study group concerned and any costs involved may need to be met by the applicants.

6.8 These facilities will be sustainable only through cooperation between nephrologists and the UKRR. There is a need for high-quality and comprehensive data entry at source.

6.9 Centres will need to develop an 'annual informatics plan', to review the maintenance and improvement of data collection, organisation and returns to the UKRR. This will help maintain the accuracy, timeliness and completeness of clinical data and also in parallel, support the career development of informatics staff.

\section{A:7 The role of the UK Renal Registry for trust managers}

7.1 As the basis of the clinical governance initiative, the gathering and presentation of clinical data are regarded as essential parts of routine patient management in the health service.

7.2 One of the principles of health service informatics is that the best data are acquired from clinical information recorded at the point of health care delivery.

7.3 Renal services data entered on local systems by staff directly engaged with patients are likely to be of the highest quality and it is these that the UKRR intends to capture.

7.4 The UKRR provides a cost-effective source of detailed information on renal services.

7.5 The regular reports of the UKRR supply details of patient demographics, treatment numbers, treatment quality and outcomes. Data are compared with both national standards and national performance, for benchmarking and quality assurance. The assessment of contract activity and service delivery is possible through these data returns, without the need for further costly hospital trust or commissioner administrative activity. These data should be particularly valuable to contracts managers and those responsible for clinical governance.

7.6 Data are available on centre case mix, infrastructure and facilities.

7.7 Work is progressing on the data capture and analysis from patients with renal disease other than those requiring RRT and will become available in time (e.g. chronic kidney disease and acute kidney injury).

\section{A:8 The role of the UK Renal Registry for commissioners of health care}

8.1 Commissioners have confirmed the powerful role accurate data plays in their decisions.

8.2 Schedule 2 of the Renal Dialysis Service Specification states 'The provider will ensure that the required patient, activity and outcomes data are provided in accordance with the requirements of the UKRR'.

8.3 The UKRR provides validated, comparative reports of renal centre activity on a regular basis to participating centres. These allow assessment of centre performance across a wide range of variables relating to structure, process and outcome measures.

8.4 There are economies of scale in the performance of audit through the UKRR, since multiple local audits are not required. 
8.5 The incidence of RRT treated locally, mortality and renal transplant rates should also be of interest. The assessment of referral and treatment patterns of patients with established (end stage) renal failure by postcode analysis indicates the geographical origin. This information also allows the expression of differences relating to geography, ethnicity and social deprivation. These data may also identify potential unmet need in the population and permit assessment on the equity of service provision. In the future, the UKRR database should also provide information on nephrology and pre-dialysis patients (CKD). This will allow a prediction of the need for RRT facilities, as well as indicating the opportunities for beneficial intervention.

8.6 UKRR data are used to track patient incidence and prevalence rates over time, which allows the modelling of future demand and the validation of these predictions.

8.7 Information on the clinical diagnosis of new and existing RRT patients may help identify areas where possible preventive measures may have maximal effect.

8.8 The higher acceptance rates in the elderly, and the increasing demand from ethnic groups due to a high prevalence of renal, circulatory and diabetic disease, are measurable.

8.9 Comparative data are available in all categories for national and regional benchmarking.

8.10 The UKRR offers independent expertise in the analysis of renal services data and their interpretation, a resource that is widely required but difficult to otherwise obtain.
8.11 In 2017 the cost of supporting the UKRR core work on RRT, AKI, CKD audit and PatientView was $£ 30$ per registered RRT patient per annum, which is less than $0.01 \%$ of the typical treatment cost of a dialysis patient per annum. It is expected that this cost will need to be made explicit within the renal services contract.

\section{A:9 The role of the UK Renal Registry for national quality assurance agencies}

9.1 The UKRR audit is listed as an audit of the Healthcare Quality Improvement Partnership national clinical audit programme.

9.2 The demographic, diagnostic and outcomes data can support the investigation of clinical effectiveness.

9.3 The case mix information and comorbidity data that would allow better assessment of survival statistics remains incomplete. There is also some clinical scepticism whether 'correction' of outcome data would reflect the realities of clinical practice.

\section{A:10 References}

1 Black N. Clinical governance: fine words or action? $\mathrm{Br}$ Med J 1998;316:297-8

2 Black N. High-quality clinical databases: breaking down barriers [Editorial]. Lancet 1999;353:1205-6 
